\title{
Multidisciplinary Team Meetings for Prostate Cancer Treatment: We Can Do Much Better in Daily Life
}

\author{
Axel Heidenreich ${ }^{\mathrm{a}, \mathrm{b}}$ \\ ${ }^{a}$ Department of Urology, Uro-Oncology, Robot-Assisted and Specialized Urologic Surgery, University Hospital \\ Cologne, Cologne, Germany; ${ }^{b}$ Department of Urology, Medical University Vienna, Vienna, Austria
}

The general idea of an uro-oncology multidisciplinary team discussion (MTD) is to provide the optimal therapy to an individual patient, which derives from an interdisciplinary, evidence-based discussion of scientific and clinical data with regard to the various available treatment options done by specialists and experts in the fields of urology, oncology, radiation-oncology, pathology, radiology, and nuclear medicine.

Although the majority of international guidelines recommend a shared decision-making within MTDs for patients with locally advanced, relapsing, and metastatic prostate cancer $[1,2]$, the clinical reality looks completely different, as demonstrated recently [3]. Atwell et al. [3] evaluated the MTD referral rates depending on the tumor type at their institution between 2010 and 2015, including more than 7,500 patients. Whereas $90-100 \%$ of the patients with lung cancer or upper gastrointestinal tract cancer were referred to the MTDs, only 34 and $28 \%$ of the patients with prostate cancer and bladder cancer, respectively, were discussed in the interdisciplinary tumor board.

Betschart et al. [4] present an important retrospective study concerning the potential benefit of MTDs in the management of patients with advanced neoplasms of the upper and lower urogenital tract. The scientific analysis has its primary focus on patients with prostate cancer, which represents the most common urogenital cancer, although also patients with bladder, kidney, and testis cancer have been discussed in their weekly MTD. This paper nicely demonstrates the steps of a continuous development of MTDs in daily routine and their positive impact on the patient's perception of treatment recommendations. Basically, all patients were highly satisfied with the delivered information and the communication with the physicians.

Similar data have been reported by other groups, which report on both improved knowledge gains of physicians due to the profound discussion resulting in more optimal treatment recommendations and an improved patient perception due to the knowledge of this individual decision-making process [5-8]. In basically all cited studies, patients preferred to play an active role in the decision-making process and cited doctors at the clinic as the most helpful source of treatment-related information. Almost all patients reported satisfaction with their decision.

The introduction of new life-prolonging agents in the management of metastatic hormone-naïve and castrationresistant prostate cancer makes an interdisciplinary exchange with regard to an interdisciplinary and risk-adapted approach of utmost importance in order not to withhold any of those new medications to the patient [9]. The benefit of MTD meetings has been demonstrated throughout the various urogenital malignancies and countries, and they have been shown to result in major individual treatment changes in $40-60 \%$ of the patients $[7,10]$. However, increasing the percentage of patients discussed in MTDs does not necessarily result in an increased compliance rate

\section{KARGER}

(C) 2019 S. Karger AG, Basel 
with regard to the adherence of MTD recommendations, as demonstrated impressively by Brown et al. [11]: the proportion of patients discussed in the MTD increased from $17-59 \%$, whereas the adherence to MTD treatment recommendations remained stable at 30 and $32 \%$ during an intervention strategy. These data reflect that we can do much better in daily life and that we need to implement an internal quality control and follow-up studies to evaluate the compliance with MTD recommendations and to assess the reasons for incompliance carefully.

However, it must be emphasized that the establishment of a MTD conference on a weekly basis requires a lot of additional working time and administrative procedures [12]. It has been shown recently that patients discussed at MTD meetings were more likely to receive more accurate and complete preoperative staging and neoadjuvant/adjuvant treatment, but this meta-analysis has failed to demonstrate a significant improvement in the clinical outcome for urogenital cancer $[13,14]$. Nevertheless, evidence is consistent in showing positive consequences for patient management in multiple dimensions, which should encourage the development of structured multidisciplinary care, minimum standards, and exchange of best practices.

\section{References}

1 Parker C, Gillessen S, Heidenreich A, Horwich A; ESMO Guidelines Committee. Cancer of the prostate: ESMO Clinical Practice Guidelines for diagnosis, treatment and follow-up. Ann Oncol. 2015 Sep;26 Suppl 5:v6977.

2 Cornford P, Bellmunt J, Bolla M, Briers E, De Santis M, Gross T, et al. EAU-ESTRO-SIOG Guidelines on Prostate Cancer. Part II: Treatment of Relapsing, Metastatic, and Castration-Resistant Prostate Cancer. Eur Urol. 2017 Apr;71(4):630-42.

3 Atwell D, Vignarajah DD, Chan BA, Buddle N, Manders PM, West K, et al. Referral rates to multidisciplinary team meetings: is there disparity between tumour streams? J Med Imaging Radiat Oncol. DOI: 10.1111/17549485.12851

4 Betschart P, Babst C, Schmid S, Rothermund C, Abt D, Schwab C, et al. Shared decision making for patients with advanced urological malignancies - evaluation of a joint urological-oncological clinic model. Oncol Res Treat. Forthcoming 2019.
5 Magnani T, Bracarda S, D'Angelillo RM, Artibani W, Barni S, Beretta G, et al. Multidisciplinary teams for the proper management of patients withgenitourinary tumors: when topics set scientific societies' agenda. Tumori. 2019 Apr;105(2):161-67.

6 Colasante A, Augurio A, Basilico R, Cotroneo AR, Di Sciascio MB, Gaspari G, et al. A multidisciplinary group for prostate cancer management: A single institution experience. Oncol Lett. 2018 Feb;15(2):1823-8.

7 El Khoury R, Chahrouri M, Hachem C, Abi Zeid J, El Alam P, Abdessater M. EVALUATION OF MULTIDISCIPLINARY TEAM MEETINGS IN URO-ONCOLOGY. J Med Liban. 2016 Aug;64(2):84-90.

8 Hurwitz LM, Cullen J, Elsamanoudi S, Kim DJ, Hudak J, Colston M, et al. A prospective cohort study of treatment decision-making for prostate cancer following participation in a multidisciplinary clinic. Urol Oncol. 2016 May;34(5):233.e17-25.

9 Parker C, Heidenreich A, Nilsson S, Shore N. Current approaches to incorporation of radium-223 in clinical practice. Prostate Cancer Prostatic Dis. 2018 Apr;21(1):37-47.

10 Heidenreich A. Interdisciplinary Management of Testicular Germ Cell Tumors - More Needed than Ever! Oncol Res Treat. 2018; 41(6):354-5.
11 Brown B, Young J, Smith DP, Kneebone AB, Brooks AJ, Egger S, et al. A multidisciplinary team-oriented intervention to increase guideline recommended care for high-risk prostate cancer: A stepped-wedge cluster randomised implementation trial. Implement Sci. 2018 Mar;13(1):43.

12 Sundi D, Cohen JE, Cole AP, Neuman BP, Cooper J, Faisal FA, et al. Establishment of a new prostate cancer multidisciplinary clinic: format and initial experience. Prostate. 2015 Feb;75(2):191-9.

13 Pillay B, Wootten AC, Crowe H, Corcoran N, Tran B, Bowden P, et al. The impact of multidisciplinary team meetings on patient assessment, management and outcomes in oncology settings: A systematic review of the literature. Cancer Treat Rev. 2016 Jan;42:56-72.

14 Prades J, Remue E, van Hoof E, Borras JM. Is it worth reorganising cancer services on the basis of multidisciplinary teams (MDTs)? A systematic review of the objectives and organisation of MDTs and their impact on patient outcomes. Health Policy. 2015 Apr;119(4): 464-74. 